\title{
Revison endonasal dacryocystorhinostomies: analysis of 44 procedures*
}

\author{
Pavel Komínek ${ }^{1}$, Stanislav Červenka ${ }^{1,2}$, Tomáš Pniak ${ }^{1}, K_{\text {Karol Zeleník }}^{1}$, \\ Hana Tomášková ${ }^{3}$, Petr Matoušek ${ }^{1}$
Department of Otorhinolaryngology, University Hospital Ostrava, Czech Republic
Ophthalmology Clinic, Otrokovice, Czech Republic
Czech Republic \\ 3 Department of Epidemiology and Public Health, Faculty of Health Studies, University of Ostrava,
}

\begin{abstract}
SUMMARY Purpose: To determine the success rate of revision endoscopic dacryocystorhinostomies (DCR) and to analyse 44 revision DCRs.

Methods: The operative and postoperative data were collected in 44 revision DCRs. The corrections of associated structural anatomic alterations were performed during the surgery (resection of the scarr, the bone window creating, resection of the head of the middle turbinate, septoplasty, ethmoidectomy etc.) and the intubation was performed in all cases. Results: The follow-up interval ranged from 12 to 36 months. The 44 ReEDCRs were performed in adults and there were only 5 children under the age of 15. The surgery was performed under local or general anaesthesia. The most frequent secondary procedures were scar resections, creating a wider bone window, and partial middle turbinate resection. Four patients were excluded for their follow-up periods had not been completed. An average time of the tubes removal was 5.6 months.

The total success rate was $84.0 \%$; the success rate was $85.7 \%$ in the group with closed rhinostomy and 1/2 in the group of canalicular and rhinostomy obstructions.

Conclusions: The endonasal revision DCR is a safe and very effective surgical procedure following the failed DCRs. The correction of associated structural anatomic alterations that may be involved in the failure of previous surgeries can be easily performed.
\end{abstract}

Key words: dacryocystorhinostomy, endonasal, revision surgery, rhinostomy, endoscopic

\section{INTRODUCTION}

In spite of the fact that the revision dacryocystorhinostomy (ReDCR) is not an exceptional procedure and not mentioned in the literature very often, it is a procedure of great importance. The success rate of dacryocystorhinostomy (DCR) performed by either an external approach (EXT-DCR) or an endonasal approach (EDCR) varies depending on the experience of the surgeons ${ }^{(1-6)}$. If DCR fails, the surgeon is in a dilemma about whether or not to reoperate, which approach to use and what results may be expected ${ }^{(1,3,6-9)}$.

The goal of our study is to report our experience with 44 revision endoscopic endonasal dacryocystorinostomies (ReEDCR).

\section{MATERIAL and METHODS}

Study design

The aim of this retrospective study is to analyse revision ReEDCRs performed at the Department of Otorhinolaryngology of the University Hospital Ostrava, Czech Republic between 1995 and 2008.
Six hundred and ninety primary DCRs were performed from endonasal (675 EDCRs) and external (15 EXT-DCRs) approaches between 1995 and 2008. Fifty revision endonasal DCRs were also performed during this period due to the nasolacrimal duct obstruction persistent after the primary DCRs. Forty three of them were primarily operated endoscopically at our department, 7 at other departments (6 EXTDCRs, 1 EDCR), respectively.

Six patients with ReEDCRs were excluded for their followup period had not been completed and thus, only 44 patients with persistent epiphora were included in the study. 38 of them were women and 6 men, the age of them ranged between 4 and 83 years (mean 30.2 years), The most common inicial causes of the obstructions were primary acquired and congenital nasolacrimal duct obstructions (Table 1).

\section{Preoperative examinations}

The lacrimal system was assessed by a combination of the fluorescein dye disappearance test (FDT), taking history and 
clinical examinations (tear retention and conjunctival sac evaluation, medial canthus observation and palpation), as well as probing with a Bowman probe and syringing of the system in some cases as required, and the level of the obstruction was determined. The nasal endoscopy was performed as well to discover the causes of rhinostomy obstruction (scar, synechiae between the middle concha/nasal septum and the lateral nasal wall, and granulations). The dacryocystography was not used. CT scan was used only if the history of previous endonasal sinus surgery, previous facial trauma and/or facial malformation was present.

\section{Operative technique}

The procedures were performed under general or local anaesthesia (trimecaine $1 \%$ and tetracaine $4 \%$ ) and under the direct visualization of the rigid fiberoptic endoscope coupled to a video camera and a display unit. The $4.0 \mathrm{~mm}$ endoscopic telescopes $30^{\circ}$ with viewing angles were preferred because of their better illumination to the $2.7 \mathrm{~mm}$ endoscopes. The local anaesthesia was used if the rhinostomy scar removal was taken into consideration only (if the movement of the Bowman probe passed into the lacrimal system through the canaliculi was endoscopicaly evident on the lateral nasal under the nasal mucosa preoperatively) and in cooperated patients. Instruments for functional endonasal sinus surgery (FESS - Blakesley forceps, scissors, chisel, suction tubes, drill, etc.) and/or for septoplasty (Cottle raspatorium, knife, scissors, etc.) were used for the ReEDCRs.

The patients were positioned in the standard sinus surgical fashion. The vasoconstriction of nasal mucosa was achieved by applying pledges soaked with epinephrin 1: 10,000 at least 10 minute before the surgery, followed by a submucosal injection of $1 \%$ trimecaini containing epinephrine 1: 100,000.

At the beginning of the procedure, septoplasty under endoscopic visualisation was performed if the septal deviation had worsened the surgical access to the lateral nasal wall. If it was possible, the septal incision on the opposite side was preferred to prevent bleeding in the operation field and only deviated part of the septal cartilage was removed.

The sac location was expected to be at the junction of the superior attachment of the superoanterior attachment of the middle turbinate to the lateral nasal wall. The nasal bayonet forceps was used for its location. One jaw of the forceps was placed extranasally and its tip was located and held in the medial canthus and the other jaw placed simultaneously intranasally was in accordance with the lacrimal sac projection and located a place, where the sac can be expected and found ${ }^{(10)}$. If the lacrimal sac was found more posteriorly than it was expected and was 'covered" with the anterior ethmoids, the ethmoidectomy was performed. The anterior part of the middle turbinate was the resected with the forceps if it had not been done during the primary DCR to decrease the risk of the rhinostomy scarring or if the synechiae between the middle turbinate and the rhinostomy were observed.

The sac was then probed with the Bowman probe through the superior or inferior canaliculi. If the movement of the probe was endoscopically evident under the nasal mucosa (scar) on the lateral nasal wall, the scar was resected with help of a sickle knife and/or with Blakesley through-cutting forceps and the sac or its remnants were widely reopened.

No movement on the lateral nasal wall indicated that the bone window was small and that it had not been created properly during the primary DCR and/or the bone growth at rhinostomy was present. In these cases, the mucosa (scar) was resected on the lateral nasal wall in the place of the sac location and/or the bone window was created (10-12 $\mathrm{mm}$ in diameter) and the sac was reopened.

In the case of an obstruction of the medial part of the common canaliculus, an incision of the canalicular scar was performed with the help of a sickle knife, and/or the probe was passed transcanalicularly through the obstruction prior tubing.

Silicone intubation (mostly bicanalicular intubation) of the lacrimal system was used in all procedures to decrease the risk of scarring of the ostium; monocanalicular intubation was used in the patients with one patent canaliculus only. The nasal gauze packing including steroid ointment at level of the middle turbinate and the lacrimal sac was used at the end of the procedure to prevent bleeding.

\section{Postoperative care}

The nasal packing was removed one day after the surgery. The patients were recommended to wet their nose with saline sprays and lavages with saline for the following 6 to 8 weeks and nasal steroids were not used. The follow-up examinations (fluorescein disappearance test, inspection, nasal endoscopy in local anaesthesia with debridement of the rhinostomy) were made 1 and 4 weeks after the surgery, 3 and 12 months after the surgery and at the time if problems occurred. The patients were followed-up more frequently during the first 2 to 3 months after the surgery only if synechiae and/or granulations at rhinostomy were present.

In postsaccal obstructions, the silicone tubes were removed 4 to 6 months following the ReEDCRs and in the presaccal obstructions 8 to 9 months afterwards. The drainage of the lacrimal system was evaluated based on the history and the fluorescein dye disappearance test ${ }^{(10)}$. The anatomical therapeutic success was defined as the lacrimal system patent for irrigation and/or the new open lacrimal ostium with flowing fluorescein was visualized endoscopically.

\section{Statistics}

For the statistical analysis, the binomial confidence intervals (CI) for the success rate were calculated $(95 \% \mathrm{CI})$. For the statistical analysis of age, sex and success, the two-sample t-test and Fisher's exact test were used at the 5\% level of significance. 
Table 1. Inicial cause of the nasolacrimal duct obstructions (before primary DCRs).

\begin{tabular}{lc}
\hline CNLDO & $6(13.6 \%)$ \\
PANDO (chronic and acute dacryocystitis) & $35(79.5 \%)$ \\
Trauma, nasal operations & $2(4.5 \%)$ \\
Chronic rhinosinusitis with nasal polyps & $1(2.3 \%)$
\end{tabular}

CNLDO $=$ congenital nasolacrimal duct obstruction

PANDO = primary acquired nasolacrimal duct obstruction

Table 3. Revision EDCRs (44 cases) - procedures performed during primary and revision surgeries.

\begin{tabular}{ll}
\hline procedure & \\
\hline resection of the scar at rhinostomy & 44 \\
wider bone window & 19 \\
partial middle concha resection & 19 \\
$\begin{array}{l}\text { removal of synechy between septum and nasal wall } \\
\text { (without septoplasty) }\end{array}$ & 2 \\
anterior ethmoidectomy & 4 \\
septoplasty & 3 \\
$\begin{array}{l}\text { intubation bicanalicular/monocanalicular } \\
\text { (average extubation - months) }\end{array}$ & $43 / 1$ \\
\hline
\end{tabular}

\section{RESULTS}

Six hundred and ninety primary EDCRs were performed in adults and children for the relief of the lacrimal obstructions at our clinic from 1995 to 2008.

There were 50 revision EDCRs carried out at our department in that period. Six patients of the 50 ReEDCRs were excluded for their follow-up period had not been completed and thus only 44 ReEDCRs were analysed in the study (38 EDCRs, 6 EXT-DCRs).

The 44 ReEDCRs were performed predominately in adults (39 cases) and there were only 5 children under the age of 15 (Figure 1), the average age of the patients was 49.8 years (ranging from 3 years to 83 years). The surgery was performed in 38 women and 6 men, 36 times unilateraly (17 right, 19 left) and 4 times bilateraly (twice at the separate sittings, 2 times simultaneously).

In the 44 ReEDCRs, the most common initial causes of the obstructions were primary acquired and congenital nasolacrimal duct obstructions (Table 1). The causes of the obstruction in patients undergoing ReEDCRs were scarring in the rhinostomy with/without bone growth in the rhinostomy (26 cases), the scarring of the middle turbinate on the lateral nasal wall and rhinostomy (12 cases), granulations at rhinostomy (1 case) and synechiae between septum and rhinostomy (3 cases). The combined obstruction (rhinostomy obstruction
Table 2. Revision EDCRs (44 cases) - locations and cause of obstructions.

\begin{tabular}{ll}
\hline rhinostomy scarring and/or new bone growth & 26 \\
$\begin{array}{l}\text { synechiae between rhinostomy and the the } \\
\text { middle turbinate }\end{array}$ & 12 \\
granulations at rhinostomy & 1 \\
$\begin{array}{l}\text { synechiae between septum and rhinostomy } \\
\text { common canaliculus + rhinostomy obstruction }\end{array}$ & 3 \\
\hline
\end{tabular}

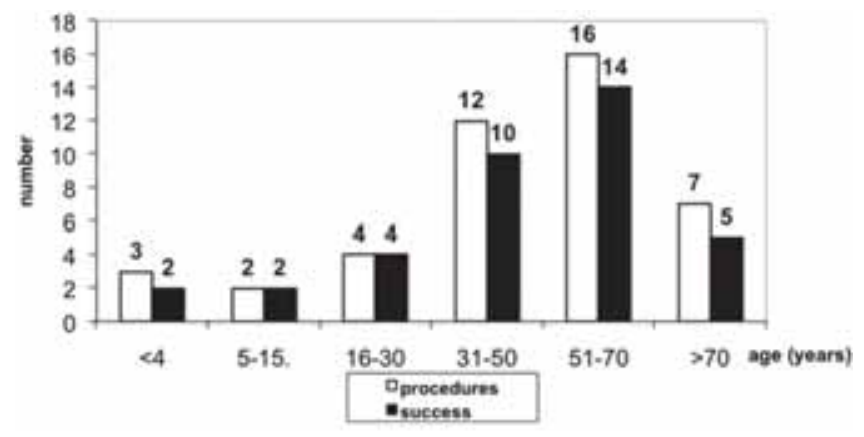

Figure 1. Revision EDCRs.

Results of 44 procedures according to the age.

and common canaliculus obstruction) were found in 2 cases (Table 2).

The time interval from the initial surgery to the development of symptoms varied from 2 weeks to 6 years (average 3.1 months), the failure developed mostly during the first 8 weeks after the primary DCRs. The time interval from the initial surgery to the revision ReEDCRs varied from 1 months to 32 years; the ReEDCRs were mostly performed between 3 and 10 months after the primary DCR.

The revision EDCRs were performed under local (17 cases) or general (27 cases) anaesthesia. The rhinostomy scar resection was the most frequent procedure (44 times) and a wider bone window was created in 19 patients, partial middle concha resection in 19 patients, septoplasty in 3 patients and anterior ethmoidectomy in 4 cases (Table 3). Agger nasi cells were opened in 2 cases. No serious complications were observed after the ReEDCRs.

The intubation was used in all cases (100.0\%), an average time for the tubes removal was 5.6 months (range from 2 to 13 months). An early displacement and removal of the silicone tube were observed once and a synechia between the lateral nasal wall and septum was found in 3 cases postoperatively. Canalicular slitting was observed in 4 patients with the tubes in place longer than 6 months. 
The success rate was $37 / 44(84.0 \%)$ in the ReEDCRs (Figure 1). The success rate was $36 / 42(85.7 \%)$ in the group with the closed rhinostomy (group I) and $1 / 2(50.0 \%)$ in the group of canalicular + rhinostomy obstructions (group II). The procedures were successful in $4 / 5(80.0 \%)$ of all children under 15 years of age. No significant differences in the success rate were found according to the age and sex in our study.

There were 7 ReEDCRs associated with a failure and the rhinostomy closure. The second revision surgeries were performed in 5 out of these 7 (4 times under general and 1 case under local anaesthesia). In all cases, the rhinostomy closure was detected, followed by a scar resection and intubation. The second revision DCR procedures were successful in 3 of 5 operations $(60.0 \%)$. In one of the 2 failured ReEDCRs, the third revision EDCR was performed with a complete success (a 56 year old woman).

\section{DISCUSSION}

The revision dacryocystorhinostomy (ReDCR) is not an exceptional procedure, nevertheless, they are not mentioned in the literature very often. That is the reason why it is difficult to evaluate all benefits of ReDCRs and if primary DCR fails, the surgeon is in a dilemma about whether or not to reoperate.

The primary failure rates of external DCRs were observed in fewer cases than $10 \%{ }^{(12,13)}$, whereas primary failure rates of endoscopical DCR ranged from 10 to $33 \%^{(2,5,14,15)}$. The most common cause of a failure is an occlusion of the rhinostomy with the cicatricial tissue and/or with bone growth ${ }^{(1,7,12,13)}$.

Welham and Handerson used dacryocystography in their study of DCRs failures in a follow-up period of 1.7 years ${ }^{(16)}$. They concluded that 61 percent of failures had been caused by an inadequate osteotomy and 39 percent due to the canalicular obstructions ${ }^{(16)}$. Also in their study of 208 failed DCRs published in 1987, Welham and Wulc observed a pure rhinostomy problem in $52 \%$ cases ${ }^{(7)}$. They found an inappropriate size or location of rhinostomy in 111 cases, scarring within rhinostomy in 28 cases, obstructions of the common canaliculi in 108 cases, interventing ethmoid in 15 cases and sump syndrome in 10 cases, respectively ${ }^{(7)}$. This does not correspond with a study of 18 failures performed by McLachlan et al. ${ }^{(4)}$. In this study, the canalicular obstruction was found in $14 / 18$ cases and the closed rhinostomy only in $4 / 18$ cases ${ }^{(4)}$. That is why only a gentle proging with a $0-0$ Bowman probe through the canaliculus is recommended (4). Unlike their findings, we discovered only two iatrogenic medial obstructions of common canaliculus following primary DCRs that may have been caused by an agressive probing were found ${ }^{(13)}$.

Although canalicular obstructions are not quite optimal indications for DCRs, we indicate EDCR (primary or secondary surgery) in some cases with obstruction of medial part of the common canaliculus and after the detailed discussion with the patients. It is important to explain them all therapeutic alternatives (canaliculo-DCR or conjunctivocystorhinostomy with Jones tube) in detail and lower success rate that should be expected in these cases. The patients must be also informed that other surgery may follow in unsuccessful cases. Thus, we believe the surgery can be indicated if only one canaliculus is patent, nevertheless also in cases with obstruction of medial part of the common canaliculus.

We do not use dacryocystography (DCG) before ReEDCR because we did not find any major contribution for the revision surgery. We are convinced that we are able to distinguish easily the important information (the size of the bone window, relation between the bone window and the lacrimal sac, obstruction of the canaliculi) prior/during the surgery with probing, nasal endoscopy and bayonet forceps ${ }^{(10)}$.

Our study confirmed that the failures of DCRs developed mostly during the first 8 weeks. The fundamental question is what is the reason for a rhinostomy closure. The main causes of the failures are an inappropriate site or location of the ostium ${ }^{(3,7,17)}$ and the closure is often attributed to the middle turbinate ${ }^{(3,7,9,17,18)}$. The scarring of the middle turbinate to the lateral nasal wall can easily develop after the mucous membrane traumatisation, especially if the middle turbinate is located near the rhinostomy or overlapping the rhinostomy. In these cases, it seems to be necessary to trim (resect) the head of the turbinate (or trimming) to expose the area and to decrease the risk of scarring after the operation as much as possible in the primary of revision EDCRs ${ }^{(5,18)}$. For the lacrimal sac location using the bayonet forceps seems to be very useful ${ }^{(10)}$. The procedure takes up 3-6 seconds and can be performed not only at the beginning of ReEDCR but can also be easy repeated at any time during the surgery ${ }^{(10)}$.

It is also believed that the bone growth may be the cause of the failure, because the reformed ostia were seen more frequently in children $(24 \%)$ than in adults $(6 \%)$ at the time of ReEDCRs and bone growth was more rapid in a growing child ${ }^{(7)}$. Nevetherless, we cannot confirm this observation based on ours and other studies ${ }^{(11)}$.

The current data may give an answer to the question whether or not to use the endonasal aproach for revision DCRs. The endonasal approach offers a much higher spectrum of surgical procedures and possible ways how to increase the chances of the surgical success ${ }^{(5,8)}$. Especially in the ReEDCRs, the endoscopy allows a correction of associated nasal factors that may have been involved in the failure of the previous surgeries to be easily performed endonasally ${ }^{(3,5,8,12)}$. Moreover, the endoscopic revision can be utilized as an out-patient procedure and safely performed under local anaesthesia ${ }^{(12)}$. Our experience confirmed that the local anaesthesia can be used in patiens having obstruction of the bone window caused by the scarr (granulations) and in the cases in which the middle turbinate 
resection had been performed during the primary surgery. The ReEDCR is very easy in these cases and the compliance of the patients is good. The age, cooperation of the patiens and other criteria must be taken into consideration and all these aspects must be discussed with the patient in great detail.

Many surgeons incorporate the silicone intubation into the primary and secondary (revision) DCR procedures, but the fact whether the silicone intubation is of great importance to ReDCRs remains unclear and controversial ${ }^{(5)}$. While we use intubation in children and in the patients with a narrow nasal cavity and canalicular obstructions in the primary DCRs, in ReEDCRs, we use the intubation in all cases. Occasionally, also mitomycin $\mathrm{C}$ or injection of betamethasone may be used to enhance the likelihood of the surgical success ${ }^{(12,19)}$, nevertheless, we have no experience in these methods in ReEDCRs.

What results can be expected in the revision DCRs? The success rate of the second external DCR is about $85 \%{ }^{(7)}$, the success rate of endoscopic DCRs in revision cases is $75-85 \%$ $(8,20,21)$. El-Guindy et al., in their study of 18 ReEDCRs after unsuccessful EXT-DCR, reported success in 15 patients $83.3 \%{ }^{(20)}$. Demarco was successful in 10 of 11 ReDCRs ${ }^{(8)}$. In our study, the success rate of ReEDCRs was $37 / 44$ (84.0\%), the second revision was successful in 3 of 5 reoperations. The success rate was $8 / 9(90.0 \%)$ in patients under 30 years of age and the success rate in patients over 30 years of age was significantly lower.

The endonasal approach avoids a skin incision, it does not disrupt the medial canthal structures, the bleeding control in the nose is much better, and the cause of the obstruction (mostly an occlusion of the rhinostomy with the cicatricial tissue) can be easily removed. Thus the endonasal approach and visualisation can be advantageous especially in the failure of primary EXT-DCR or EDCR resulting from scarring and obstruction intranasally.

\section{CONCLUSION}

The revision endonasal DCR is a safe and efficatious surgical procedure for patients with the tenacious epifora following unsuccessful external or endonasal DCRs. The correction of associated intranasal structural anatomical alterations that may have been involved in the failure of previous surgeries can be easily performed. A success rate of ReEDCRs is high and provides satisfactory outcomes.

\section{ACKNOWLEDGMENT}

The authors would like to thank Mrs. Zdena Závadová and Mr. Jiří Hynčica for their help and corrections to get this paper in its final form.

\section{AUTHOR CONTRIBUTIONS}

We certify that we have participated sufficiently in the conception and design of this work and the analysis of the data and the writting of the manuscript, to take public responsibility for it. Neither this manuscript nor one with substantially similar content under our authorship has been published or is being considered for publication elsewhere.

We have read and approved the contribution. We certify that written permission from all persons named in the acknowledgments has been obtained.

The shares of the authors with the autorship and analysis are: P. Komínek 50\%, S. Červenka 10\%, T. Pniak 10\%, K. Zeleník $5 \%$, H. Tomášková $10 \%$, P. Matoušek $15 \%$.

\section{CONFLICT OF INTEREST STATEMENT}

We have no potential or actual conflicts of interest with this manuscript.

The total responsibility for the integrity of the content of the manuscript is by P. Komínek.

Proprietary interest statement: There is no type of financial interest that is related to the manuscrip, including stock or ownership of a business entity connected to a product described in the paper, paid consulting for the company or competing companies, or patent rights to a drug or piece of equipment.

\section{REFERENCES}

1. Woog JJ, Kennedy KK, Custer PL, et al. Endonasal Dacryocystorhinostomy. A Report by the American Academy of Ophthalmology. Ophthalmology. 2001; 108: 2369-2377.

2. Hartikainen J, Grenman R, Puukka P, et al. Prospective randomized comparison of endonasal endoscopic dacryocystorhinostomy and external dacryocystorhinostomy. Ophthalmology. 1998; 106: 1106-1113.

3. Önerci M, Orhan M, Ögremenoglu O, et al. Long-term results and Reasons for Failure of Intranasal Endoscopic Dacryocystorhinostomy. Acta Otolaryngol. 2000; 120: 319-322.

4. McLachlan DL, Shannon GM, Flanagan JC. Results of Dacryocystorhinostomy: Analysis of the Reoperations. Ophthalmic Surgery. 1980; 11: 427-430.

5. Cohen AJ, Waldrop FC, Weinberg DA. Revision Dacryocystorhinostomy. In Cohen AJ, Mercandetti M, Brazzo BG (Edts) The Lacrimal System. Berlin: Springer, 2006; 244-254.

6. Metson R, Woog JJ, Puliafito CA. Endoscopic laser dacryocystorhinostomy. Laryngoscope. 1994; 104: 269-274.

7. Welham RAN, Wulc AE. Management of unsuccessful lacrimal surgery. Br J Ophthalmol. 1987; 71: 152-157.

8. Demarco R, Strose A, Araújo M, et al. Endoscopic revision of external dacryocystorhinostomy. Otolaryngol Head Neck Surg. 2007; 137: 497-499.

9. Önerci M. Dacryocystorhinostomy. Diagnosis and treatment of nasolacrimal canal obstruction. Rhinology. 2002; 40: 49-65.

10. Komínek P, Červenka S, Matoušek P. Endonasal Dacryocystorhinostomy: Location of Lacrimal Sac with Forceps. Laryngoscope. 2004; 114: 1674-1676.

11. Komínek P, Červenka S, Matoušek P, et al. Primary pediatric endonasal dacryocystorhinostomy - a review of 58 procedures. Int J Pediatr Otorhinolaryngol. 2004; 74: 661-664.

12. Watkins LM, Janfaza P, Rubin PAD. The Evolution of Endonasal Dacryocystorhinostomy. Surv Opthalmol. 2003; 48: 73-84.

13. Allen K, Berlin AJ, Levine HL. Intranasal endoscopic analysis of dacryocystorhinostomy failure. Ophthalmic Plast reconstr Surg. 1988; 4: 143-145.

14. Zilelioglu G, Ugurbas SH, Anadolu Y, et al. Adjunctive use of mitomycin $\mathrm{C}$ on endoscopic lacrimal surgery. Br J Ophthalmol. 1998; 82: 63-66. 
15. Mannor GE, Millman AL. The pronostic value of preoperative dacryocystography in endoscopic intranasal dacryocystorhinostomy. Am J Ophthalmol. 1992; 113: 134-137.

16. Welham RA, Hendeson PH: Results of dacryocystorhinostomy. Trans Ophthalmol UK. 1977; 93: 601-609.

17. Sham CL, van Hasselt CA. Endoscopic terminal dacryocystorhinostomy: Laryngoscope. 2000; 110: 1045-1049.

18. Rebeiz EE, Shapshay SM, Bowlds JH, et al. Anatomic Guidelines for Dacryocystorhinostomy. Laryngoscope. 1991; 102: 1181-1184.

19. Zeldovich A, Ghabrial R. Revision Endoscopic Dacryocystorhinostomy with Betamethasone infection under Assisted local Anaesthetic. Orbit. 2009; 28: 328-331.

20. El-Guindy A, Dorgham, A, Ghoraba M. Endoscopic revision surgery for recurrent epiphora occuring after external dacryocystorhinostomy. Int Ophthalmol Clin. 1999; 39: 177-184.

21. Boush GA, Lemke BN, Dortzbach RK. Results of endonasal laser-assisted dacryocystorhinostomjy. Ophthalmology. 1994; 101: $955-959$.

Pavel Komínek, MD, PhD, MBA

University Hospital Ostrava

Department of Otorhinolaryngology

17. listopadu Street 1790

70852 Ostrava

Czech Republic

Tel: $+420-597-375801$

Fax: +420-596-917 340

E-mail: pavel.kominek@fno.cz

\section{SOCIETY NEWS}

\section{CALL FOR PAPERS}

\section{RESEARCH PRIZES 2012 of the EUROPEAN RHINOLOGIC SOCIETY}

The European Rhinologic Society biennially awards two Research Prizes; one prize is awarded for original basic research, and the second for an original clinical research in the field of Rhinology. In 2012 again, these prizes will be awarded, and therefore ENT Residents and Fellows are kindly requested to apply. Entries will have to meet the following conditions:

- $\quad$ Entries are to be submitted in the form of a scientific paper. Papers that have been accepted for publication by an international scientific journal will also be considered. Scientific papers - as well as supplements and Ph.D.theses - that have already been published are excluded from competition.

- The research paper submitted is either the result of individual research activities or resulting from a team effort. In the latter case the first author will be considered as the nominee.

- $\quad$ Each applicant is allowed one entry. The author indicates whether the paper is a basic research or a clinical study. (We define clinical research as studies that deal with patients or normal subjects in a clinical set-up, whereas basic research refers to studies performed with either animals or tissues taken from patients or normal subjects).

- $\quad$ Only candidates below the age of 40 years can apply.

- The executive Committee of the European Rhinologic Society, supported by a number of invited expert referees, will act as the jury and will select both prizewinners.

- $\quad$ The prizes, each of which amounts to $€ 1.500$,- will be awarded during the Opening Ceremony of the next ERS Congress in Toulouse (France), June 17-21, 2012. The prizewinners will be invited to attend the congress, free of charge. The prize-winning entries will be given priority when submitted to the Journal Rhinology.

Applications of the submitted papers should be directed before February 1, 2012 to Mrs Margalith van Huiden by Email (m.b.vanhuiden@amc.uva.nl) 